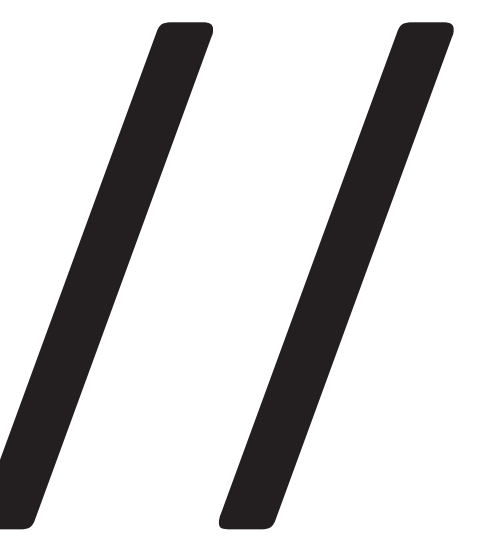

\title{
Cinema, intermidialidade e métodos historiográ- ficos: o Árido Movie em Pernambuco
}

Cinema, intermediality and historiographic methods: the Árido Movie in Pernambuco

Samuel Paiva ${ }^{1}$ 
Dossiê A pesquisa em cultura audiovisual: novos desafios e aportes teóricos Cinema, intermidialidade e métodos historiográficos: o Árido Movie em Pernambuco | Samuel Paiva

Resumo: o artigo diz respeito à historiografia do cinema, procurando investigar a possibilidade de compreensão da intermidialidade como método historiográfico. Parte das proposições de Lúcia Nagib sobre "políticas da impureza", por sua vez pautadas pela noção de "cinema impuro", de André Bazin, cotejando-as com os "fenômenos intermidiáticos" apresentados por Irina Rajewsky e também com a "historiografia de metodologias" da intermidialidade nos filmes, tal como proposta por Ágnes Pethö. Como estudo de caso, considera a produção do cinema de Pernambuco, com maior interesse no longa metragem Baile perfumado (1996), embora referindo outras obras dos anos 1990 aos dias atuais.

Palavras chave: cinema e intermidialidade; método historiográfico; cinema e música em Pernambuco.

Abstract: the article concerns to the history of cinema, looking into the possibility of understanding intermediality as a historiographic method. It starts with Lúcia Nagib’s propositions about "politics of impurity", in turn guided by André Bazin’s notion of "impure cinema", comparing them with the "intermedial phenomena" presented by Irina Rajewsky and the "historiography of methodologies" on films' intermediality, as proposed by Ágnes Pethö. As a case study, it considers the production of cinema in Pernambuco, with increased interest in the feature Perfumed ball (1996), while also referring other works from the 1990s to nowadays.

Key word: cinema and intermediality; historiographic method; cinema and music in Pernambuco. 
O cinema sempre se relacionou com outras artes, como propôs Bazin (2013) em sua defesa do "cinema impuro", em um texto primeiramente publicado em meados da década de 1950: "Pour un cinéma impur - défense de l'adaptation". Mais recentemente, tal noção vem sendo retomada por Lúcia Nagib, que propõe a ideia de "políticas da impureza" no âmbito dos estudos sobre intermidialidade, com interesse em investigar como uma abordagem intermidiática pode promover um método historiográfico, procurando perceber os diálogos interculturais propiciados pelas diversas mídias na história do cinema brasileiro. Segundo a própria pesquisadora, o seu interesse é...

investigar as políticas de hibridização colocando o fenômeno intermidiático não como um projeto acabado ou um fim em si mesmo, mas como um problema, quer dizer, o lugar de uma crise, a falta de uma mídia que requisita outra, procedimentos metafóricos na perspectiva de preencher uma lacuna que está no próprio núcleo da criação artística (NAGIB, 2014, p. 21).

Basicamente é a questão da "crise" que vai nos colocar diante do cinema e da música pernambucana como objeto instigante às reflexões sobre um método historiográfico pautado pela intermidialidade, sobretudo, no que diz respeito às relações entre a produção cinematográfica que se desenvolve a partir dos anos 1990, na chamada "retomada do cinema brasileiro", como propõe a própria Nagib (2002) em outro texto. Antes, porém, da discussão acerca das relações intermidiáticas entre cinema e música em Pernambuco, convém uma organização inicial dos parâmetros teóricos a partir dos quais a questão pode ser colocada.

A questão baziniana do cinema impuro é reconsiderada e ampliada por Lúcia Nagib na conexão que a autora estabelece com a "política do dissenso", tal como formulada por Jacques Rancière (2010). Contudo, o alcance da discussão começa bem antes, desde Bazin. Vale lembrar que, para ele, no referido texto publicado na década de 1950, o cinema não consiste em um meio autossuficiente, como postulavam defensores do "cinema puro", por exemplo, artistas de várias artes e cineastas vanguardistas dos anos 1920 e 1930 (René Clair, Man Ray, Fernand Léger, entre outros), que por vezes inclusive privilegiavam as formas visuais às formas sonoras, em um momento de transição do cinema silencioso para o cinema sonoro sincronizado. Como janela para o mundo, na perspectiva do cinema baziniano, o som era bem vindo, como também eram as adaptações literárias e teatrais que, pelo meio cinematográfico, poderiam chegar a muitos mais espectadores além da elite letrada.

Mas há também tensões nesse projeto tão abrangente de Bazin. Segundo os 
argumentos de Nagib, existe uma utopia ou mesmo contradição, na medida em que por vezes, para ele, o público também pode ser um problema, por exemplo, quando não reconhece as obras que, na perspectiva do crítico francês, deveria reconhecer. Além disso, acerca de cinema impuro ou puro, tensões também vão ocorrer no contexto da Nouvelle Vague, no qual a questão do "autor", de acordo com as concepções da "política dos autores", estava atrelada à busca de um específico fílmico, aspecto por vezes contestado pelo próprio Bazin.

A questão autoral chega ao âmbito do pós-estruturalismo, com autores como Barthes e Foucault, assumindo a referência ao dialogismo de Bakhtin e à intertextualidade de Kristeva, para pensar o autor não propriamente como uma pessoa, mas como uma instância de um discurso que se articula a partir de discursos pré-existentes. O que nos interessa aqui é justamente a dimensão de hibridização intercultural implicada na intermidialidade, tal como propõe Lúcia Nagib tomando agora, como parâmetro, colocações de Robert Stam. Nas palavras dela:

Barthes e Foucault certamente não estavam sozinhos em recusar a autoria e, de fato, como Robert Stam observa, isto foi amplamente corroborado por estruturalistas e pós-estruturalistas, que substituíam ideias de pureza, essência e origem por aquelas de intertextualidade e dialogismo, tais como representadas respectivamente por Kristeva e Bakhtin, este último um defensor, tanto quanto Foucault, do autor como uma 'orquestração de discursos pré-existentes' [...] (NAGIB, 2014, p. 26).

Já mais recentemente, ou seja, nestes tempos de internet, a noção baziniana de impureza continua plenamente válida. A mudança de espaços de espectatorialidade, por exemplo, das salas de cinema para as telas de computador, as autorias coletivas possíveis nos ambientes da web, e as redes sociais são espaços de plena comunicação cross-media, nos quais tanto se dá a criação quanto a crítica. E isso já havia sido previsto pelo próprio Bazin. Por outro lado, entretanto, algumas dicotomias para as quais ele foi figura fundamental, por exemplo, a distinção entre cinema clássico e moderno, por vezes retomada em outras chaves, tais como a "imagem-movimento" e a “imagem-tempo", de Deleuze (2006; 2009), vêm sendo questionadas². E isso significa um impacto considerável no campo dos estudos e nas metodologias relacionadas à história do cinema.

Na base desse impacto, está a ideia do cinema como objeto político. Tanto o cinema impuro quanto o realismo baziniano pressupunham mais uma existência da

\footnotetext{
2Um dos exemplos citados por Nagib é o artigo de Miriam Hansen, "The mass production of the sense: classical cinema as vernacular modernism”, no qual são discutidas formas mais complexas de proposição da história do cinema, para além da distinção clássico/moderno (NAGIB, 2014, p. 29).
} 
própria realidade humana do que sua possível essência. Por exemplo: a profundidade de campo e o plano sequência, em oposição à montagem, proporcionam, segundo a visão de Bazin, por sua vez inspirada na concepção sartreana de liberdade existencial da escolha, uma espécie de ambiguidade da expressão oportuna à própria realidade. Tal indistinção entre arte e realidade prevê a intermidialidade. E isso pode ser comprovado em distintos momentos da história da arte, por exemplo, com a noção de obra de arte total, de Wagner, que pensava na superação de fronteiras de expressões artísticas como forma de alcançar a amplitude da própria vida.

Ainda seguindo os argumentos de Nagib, sua noção de política chega à concepção de "dissenso", nos termos de Rancière, que, entre outras questões, entra no debate ao se opor à distinção sobre cinema clássico/moderno, ao criticar a arte didática, ao tratar da dimensão política na perspectiva de um "regime estético". Nagib cita o seguinte trecho de Rancière: "Se existe uma conexão entre arte e política, ela deve ser proposta em termos de dissenso, o próprio núcleo do regime estético: obras de arte podem produzir efeitos de dissenso precisamente porque não dão lições nem têm qualquer destinação" (apud NAGIB, 2014, p. 30). Ela procura pensar tal chave conceitual no campo da história do cinema, questionando paradigmas diacrônicos convencionais - clássico e moderno, por exemplo -, associando a noção de dissenso à de intermidialidade, na medida em que o recurso a mídias diversas em um filme tende, em sua visão, a suspender o eventual caráter didático da obra, introduzindo dilemas. A concepção de dilema, no sentido de uma crise dialética, de fato, é central em seu projeto, como diz a própria pesquisadora:

Minha intenção aqui é sugerir uma rota alternativa que coloca a intermidialidade não como um objetivo político projetado para o futuro, mas como uma crise dialética sempre presente, o lugar de um profundo dilema entre a condução depurativa inerente a todas as formas artísticas e a consciência de sua insuficiência. Esse dilema, eu sugiro, é político por sua própria natureza.

Esta seria então uma abordagem propícia ao método historiográfico pautado na intermidialidade na medida em que atualiza a questão baziniana fundamental: o que é o cinema? Aqui vamos testar tal abordagem de modo a compreender o que é o cinema pernambucano, em termos de uma história que possa ser construída a partir de tais parâmetros intermidiáticos. Como dado inicial incontornável há o fato de que existe uma forte relação entre esse cinema que se dá a partir dos anos 1990 e o Movimento Mangue, cuja expressão mais forte, eclodindo no mesmo período, é a música, ainda que chamando para uma experiência entre várias mídias, todas convo- 
Cinema, intermidialidade e métodos historiográficos: o Árido Movie em Pernambuco | Samuel Paiva

cadas a responder a uma crise percebida pelos próprios artistas na cidade de Recife, capital de Pernambuco, naquele momento.

Há, de fato, como alguns estudos já apontaram (LEÃO, 2002, 2008; FONSECA, 2006; NOGUEIRA 2009), uma forte conexão entre o Árido Movie, ou Cinema do Mangue, e a música do Manguebeat, um cruzamento que, sem dúvida, é um ponto de inflexão fundamental, no sentido de um estudo de caso que possa dizer respeito a um método historiográfico voltado ao cinema brasileiro na perspectiva da intermidialidade. O termo "Árido Movie", ${ }^{2}$ vale lembrar, foi criado pelo jornalista Amin Stepple em meados dos anos 1990 para designar filmes pernambucanos então realizados no diálogo com o Manguebeat, o movimento musical que, articulado em torno de bandas como Chico Science \& Nação Zumbi e Mundo Livre S/A (NOGUEIRA, 2009, p. 85), confirmava-se com os respectivos discos Da lama ao caos e Samba esquema noise, ambos de 1994. Algum tempo depois, foi lançado o filme Baile perfumado (1996) de Lírio Ferreira e Paulo Caldas, que contava entre os autores da sua trilha sonora justamente com integrantes das bandas mencionadas, além de outras, como Mestre Ambrósio, cujos músicos eventualmente aparecem como atores coadjuvantes em algumas cenas.

Desde então, é reconhecível como uma característica recorrente de várias produções cinematográficas e audiovisuais pernambucanas a sua conexão com a música produzida no Recife e em seus arredores, o que, além do referido Baile perfumado, pode ser observado também em outros curtas e longas metragens, além de videoclipes, programas de rádio e de TV, instalações, etc. ${ }^{4}$ Observado tal conjunto, reitera-se em seus discursos a intenção de ressaltar o trabalho produzido por músicos relacionados ao Manguebeat. Em alguns desses filmes, há uma instrução de leitura fílmica, como diria Roger Odin (2012), que expõe a música como um dado fundamental, inclusive, no que diz respeito às tensões entre ficção e documentário. Essas tensões aproximam interseções entre o Árido Movie e o Manguebeat, por exemplo, relacionadas à crise perceptível na cidade do Recife, a qual é explicitada no manifesto Caranguejo com cérebro, lançando em 1992, marco do movimento que, em resposta à crise, propõe um circuito energético midiático:

\footnotetext{
${ }^{3}$ O termo foi incorporado como título do longa metragem Árido movie (2006), de Lírio Ferreira.

${ }^{4}$ Considerando os longas, além do Baile perfumado, há filmes tais como O rap do pequeno príncipe contra as almas sebosas (2000), de Paulo Caldas e Marcelo Luna, Amarelo Manga (2003) de Cláudio Assis, Cinema, aspirinas e urubus (2005), de Marcelo Gomes, Árido movie (2006), de Lírio Ferreira, Baixio das bestas (2006), de Cláudio Assis, Deserto feliz (2007), de Paulo Caldas, entre outros. Em relação à produção mais recente, poderiam ser mencionados, por exemplo, Era uma vez eu, Verônica (2012), de Marcelo Gomes, O som ao redor (2012), de Kleber Mendonça Filho, Amor, plástico e barulho (2013), de Renata Pinheiro, Tatuagem (2013), de Hilton Lacerda, entre outros.
} 
Em meados de 91 começou a ser gerado e articulado em vários pontos da cidade um núcleo de pesquisa e idéias pop. O objetivo é engendrar um 'circuito energético', capaz de conectar as boas vibrações dos mangues com a rede mundial de circulação de conceitos pop. Imagem símbolo, uma antena parabólica enfiada na lama" (apud VARGAS, 2007, p. 66). ${ }^{5}$

Há aqui um dado histórico presente no próprio manifesto, que propõe um circuito midiático com o propósito de reverter a crise da cidade e projetá-la no mundo (daí inclusive as expressões em inglês presentes nos dois termos: Manguebeat e Árido Movie). Considerado tal contexto, como pensar um método historiográfico partindo da intermidialidade entre o Árido Movie e o Manguebeat? De um lado, alguns referenciais teóricos e metodológicos já bem consolidados em relação à historiografia do cinema permanecem em pauta, por exemplo, Jean-Claude Bernardet (1995) e as questões que ele aponta, entre outros trabalhos, em sua Historiografia clássica do cinema brasileiro. Com base em suas proposições, podemos levantar a hipótese de que existem "linhas de coerência" permitindo a possibilidade de uma historiografia que tenha como prerrogativa a intermidialidade entre cinema e música, no caso aqui estudado. A propósito da proposta metodológica de Bernardet, vale de fato observar como vários de seus argumentos coincidem em grande medida com as premissas teóricas que foram apresentadas a partir de Lúcia Nagib, por exemplo, o interesse no circuito multimidiático - imprensa, teatro, literatura - como forma de compreender os primeiros tempos do cinema no Brasil.

Mas, por outro lado, focando-se especificamente a questão da intermidialidade como problema epistemológico, uma das referências mais notáveis é Irina Rajewsky (2012), que compreende a intermidialidade como qualquer fenômeno midiático que envolva mais de uma mídia, como diz, "qualquer fenômeno que conforme o prefixo inter indica - ocorra no espaço entre uma mídia e outra(s). Logo, o cruzamento de fronteiras midiáticas vai constituir uma categoria fundadora da intermidialidade [grifos da autora]" (RAJEWSKY, 2012, p. 52). Tal dimensão de fronteira, que pressupõe um espaço entre uma mídia e outra(s), de fato nos obriga a fazer uma opção sobre qual das mídias relacionadas será privilegiada em termos de uma abordagem historiográfica. A opção é por uma história do cinema, no caso, sobre o Árido Movie, privilegiando-se os filmes, considerados em seus textos e contextos de

\footnotetext{
${ }_{5}^{5}$ A rigor, na base desse manifesto e do movimento que ele deflagra, estão dadas referências anteriores igualmente investidas de uma dimensão social abrangente, por exemplo, a obra de Josué de Castro (19081973), intelectual multi e interdisciplinar, autor de títulos - como Geografia da fome (1946), Geopolítica da fome (1951) e Homens e caranguejos (1967), entre outros - que servem de parâmetro para o referido manifesto até mesmo em sua exposição do "mangue" como "conceito" fundamental, lugar de diversidade biológica, ecossistema complexo que se torna uma metáfora invocadora "de fertilidade, diversidade e riqueza", capazes de reverter a iminente falência da cidade.
} 
produção, distribuição, exibição e recepção, que constituem o lugar principal da investigação. Na observação dos filmes, por sua vez, o foco de interesse principal é a presença do Manguebeat enquanto um fenômeno eminentemente musical reconhecível nas obras fílmicas. Esse reconhecimento poderá ocorrer a partir dos três grupos de fenômenos intermidiáticos propostos por Rajewsky, a saber, (a) "transposição ou transformação midiática", (b) "combinação de mídias" e (c) "referências midiáticas".

A esse respeito, propomos um exercício partindo do filme Baile perfumado, que justamente é uma produção emblemática do Árido movie, trazendo já desde o seu título a indicação de um vínculo com a música, aspecto que estará em pauta em uma narrativa que conta a história do fotógrafo e cinegrafista libanês Benjamin Abrahão - um personagem que em si suscita a dimensão intermidiática do cinema com a fotografia - na medida em que o seu empenho é fotografar e filmar o grupo de Lampião. Na concepção da trilha sonora do filme, vale destacar a presença de figuras chave do Manguebeat - Chico Science, Fred 04 e Siba, por exemplo - que por vezes também atuam em performances musicais (Siba e sua banda, Mestre Ambrósio) ou mesmo como atores em papéis coadjuvantes (Siba e Fred 04, do Mundo Livre S/A).

$\mathrm{O}$ primeiro grupo de fenômenos apontados por Rajewsky diz respeito à "transposição ou transformação midiática", que ela exemplifica lembrando a adaptação fílmica de textos literários. De fato, na relação entre cinema e literatura não parece existir maiores divergências em termos do que seria uma adaptação literária ao cinema. Há por certo um caminho já percorrido que nos permite cogitar a transposição de uma mídia à outra dentro de um determinado horizonte de abordagens, considerando literatura e cinema. Entretanto, ao se pesquisar uma transposição da música ao cinema, o que deve ser cogitado? Sua letra, melodia? Nossa hipótese é de que, sim, tudo isso. No caso do Baile perfumado há, por exemplo, a transposição da música "Salustiano song", do álbum Da lama ao caos, de Chico Science \& Nação Zumbi, para uma de suas cenas. A música em questão funciona como uma interseção entre o filme e o disco e, nesse caso, há um “valor acrescentado" (CHION, 2011) pela música ao filme, valor que vem imbuído de uma dimensão histórica, a ser perseguida na interseção entre as duas mídias. Vale lembrar que, segundo Chion "por valor acrescentado, designamos o valor expressivo e informativo com que um som enriquece uma determinada imagem, até dar a crer, na impressão imediata que dela se tem ou na recordação que dela se guarda, que essa informação ou essa expressão decorre 'naturalmente' daquilo que vemos e que já está contida apenas na imagem" (CHION, 2011, p. 12). Desnaturalizar tal informação e expressão sonora e musical, procurando considerá-las na perspectiva histórica de que estão imbuídas em outra 
mídia transposta ao filme, é o ponto a ser investigado. No caso de "Salustiano song" no âmbito do disco Da lama ao caos, afirma Herom Vargas:

A nona faixa do disco, Salustiano Song, é instrumental e homenagem a Mestre Salustiano, importante mestre popular e rabequeiro de Pernambuco. A música foi feita no estúdio de gravação e contém vários registros distorcidos de guitarra e outros efeitos, uma linha de baixo constante - como ocorre em várias músicas do grupo - e as percussões com atabaques, caixa e tambores (VARGAS, 2007, p. 148)

A música, de fato, é marcada pela forte batida do maracatu, o ritmo identificado à cultura pernambucana em sua ancestralidade de hibridações culturais de origem africana. Mestre Salustiano foi uma figura central em tal contexto. Ou seja, a transposição dessa faixa musical ao filme nos remete a uma questão de identidade cultural de um movimento bem mais amplo, além do próprio cinema, que serve para esclarecer vários sentidos históricos implicados no discurso fílmico em questão, haja vista a dimensão empática dessa inserção musical em algumas cenas, valendo lembrar que, buscando o efeito empático, “a música exprime diretamente a sua participação na emoção da cena, dando o ritmo, o tom e o fraseado adaptados, isto evidentemente em função dos códigos culturais de tristeza, da alegria, da emoção e do movimento" (CHION, 2011, p. 14).

O segundo grupo de fenômenos propostos por Rajewsky diz respeito à “combinação de mídias”, no qual a ópera, o teatro, instalações, histórias em quadrinhos, enfim, formas multimídias podem ser lembradas como exemplos. Vale destacar que, segundo a pesquisadora, um filme é a priori uma forma multimídia ou uma combinação de mídias. Entretanto, observando-se determinados discursos fílmicos, é possível a percepção de momentos da enunciação nos quais se destaca a combinação com outra mídia. Um exemplo por vezes citado pela própria Rajewsky diz respeito ao teatro. Sabe-se que existe uma dimensão teatral na mise-en-scène cinematográfica: os atores representam seus personagens, pode haver um cenário, etc. Entretanto há filmes que chamam a atenção para esta combinação com o teatro de uma forma explícita como, por exemplo, Dogville (2003), de Lars von Trier, que assume um registro plenamente teatral em sua encenação cinematográfica.

Considerando-se tal fenômeno de combinação de mídias, no caso do Baile perfumado algumas formas se destacam. Uma delas diz respeito à fotografia. Outra, ao cinema. Nos dois casos, a combinação está diretamente relacionada ao protagonista, o fotógrafo e cinegrafista Benjamin Abrahão. A narrativa, que conta a sua trajetória e mostra o seu objetivo de fotografar e filmar o grupo de Lampião, por 
vezes apresenta documentos históricos, ou seja, imagens de fato produzidas pelo fotógrafo e cinegrafista libanês. Em outros momentos essas fotos e trechos de filmes são reconstituídos e por vezes cotejados com os originais na própria montagem fílmica. Devemos a propósito notar que Benjamin não consegue cumprir o seu intento de finalizar o filme sobre Lampião, e acaba sendo assassinado.

O sentido de "morte" aqui se estende da fotografia ao cinema, numa espécie de metáfora dos vários ciclos do cinema pernambucano, que parece sempre renascer das cinzas. Não por acaso a noção de "ciclo" aparecerá em vários trabalhos relacionados à história do cinema de Pernambuco (cf. FIGUEIRÔA, 2000; CUNHA, 2006; NOGUEIRA, 2009). Note-se a propósito de Baile perfumado que o filme começa com a morte do Padre Cícero, espécie de pai adotivo de Benjamin Abrahão, e termina com a morte do próprio protagonista. Entretanto, desrespeitando a diacronia que sempre levará à morte, a um fim previsível, a montagem reverte essa previsibilidade. A questão da morte, de fato, é um tema recorrente nesse cinema produzido em Pernambuco (cf. PAIVA 2007, 2008, 2014). Mas se há um “isso foi”, como diria Barthes (1984) pensando na fotografia como algo que se remete a um instante que nunca mais poderá se repetir, e como podemos dizer nós referindo-nos tanto aos materiais de arquivo fotográficos quanto cinematográficos reapresentados no filme de Lírio Ferreira e Paulo Caldas, há também um “isto está sendo" da recriação discursiva que, ao refazer a cena, o discurso pré-existente, tensiona a temporalidade em termos de um dilema, de uma crise dialética.

No que concerne à musica, a combinação de mídias ganha destaque especial ao menos em dois momentos. Um deles diz respeito às performances musicais presentes na narrativa. O outro está relacionado a instantes nos quais o filme se investe de uma montagem cujo ritmo é mais próximo da linguagem da música ou de gêneros ou estilos com ela mais diretamente envolvidos, como o videoclipe. Em relação à primeira possibilidade destaca-se, no Baile perfumado, a presença do músico Siba e de outros integrantes da banda Mestre Ambrósio em algumas cenas em que eles atuam como músicos, efetivamente, em performances musicais. A inserção desse grupo de músicos é outro dado a corroborar uma descontinuidade temporal entre ontem e hoje. De um lado, porque a banda traz um registro ancestral em parte pela própria utilização da rabeca, instrumento musical medieval relacionado à cultura nordestina. Por outro, porque em sua inserção cênica em um filme cuja história se passa na década de 1930, mantém o seu estilo atual, seja em termos de sua sonoridade musical ou mesmo do seu comportamento cênico. Em relação ao segundo ponto, os instantes de ritmo musical, há momentos que aqui vou designar como momentos 
videoclipes ou "momentos musicais", como denomina a pesquisadora Amanda Nogueira (2009, p. 125). São instantes nos quais a montagem do filme é levada eminentemente pela música presente na cena, assumindo a eminência da forma musical na própria narrativa, o que ocorre várias vezes nesse Cinema do Mangue.

Em filmes como Baile perfumado, Amarelo manga, Árido movie, Deserto feliz, observamos, recorrentemente, a existência de sequências que poderíamos chamar "momentos musicais". Essas sequências podem estar incorporadas ao enredo (como parte do percurso narrativo geral) ou podem ser dotadas de maior autonomia em relação à própria ação dramática (marcadas por um certo "deslocamento" do enredo. Em uma ou outra situação, as sequências se caracterizam por atualizarem momentos "pop" em que o filme pára em função de mostrar a música (exibir). [...] Tais aparições poderiam ser comparáveis a uma espécie de "merchandising da cena cultural pernambucana". Podem ser consideradas também um procedimento de auto-legitimação dessa cena cultural. Nos "momentos musicais", o tratamento conferido à música nos filmes é comparável ao que ela merece em musicais e videoclipes (NOGUEIRA, 2009, p. 125).

O caráter de "merchandising" e de "legitimação dessa cena cultural" por meio dos momentos musicais nos leva a cogitar que, neste caso, a música acrescenta ao cinema um valor excepcional, inclusive, ampliando as possibilidades de inserção mercadológica. A multiplicação do filme, por exemplo, em cenas construídas como videoclipes para circularem por outras telas, além das salas de cinema, sem dúvida, é um dado a ser considerado em um instante no qual a própria televisão passa a contar com canais cada vez mais especializados em música, como a MTV Brasil, que aportava no país no início da década de 1990. Dado que nos leva à hipótese de que a crise do cinema em Pernambuco de alguma forma encontrava uma saída, naquele momento da "retomada", por meio da música, uma expressão artística que por sua vez encontrava caminhos bem mais amplos do que o cinema de então, não só no contexto da cultura pernambucana, mas do Brasil de uma maneira geral.

Já o fenômeno das "referências midiáticas" é bastante abrangente, "a exemplo das referências, em um texto literário, a um certo filme, gênero fílmico ou cinema em geral (a escrita fílmica); idem as referências que um filme faz a uma pintura, ou que uma pintura faz a uma fotografia, dentre outras"(RAJEWSKY, 2012, p. 58). É oportuno lembrar que, em alguma medida, as referências podem se confundir com transposições e combinações de mídias e vice versa. A própria Rajewsky deixa isso claro, ou seja, que essas divisões dos três fenômenos propostos por ela têm um caráter de constructo para facilitar as análises. Em todo caso, considerando-se as possíveis referências do Baile perfumado, mais uma vez o filme nos dá instruções relacionadas 
ao próprio cinema e à música, como temos observado até agora. No que diz respeito ao cinema, já foi mencionado o fato de que o protagonista é um fotógrafo e cinegrafista, e isso por si só já instaura a possibilidade de referências ao próprio cinema. Mas, mais precisamente, há uma série de referências ao Cinema Novo, especificamente, o que podemos observar já desde as primeiras cenas, por exemplo, na morte do Padre Cícero, personagem interpretado por Jofre Soares, um ícone do Cinema Novo, ator que também estará presente em outros filmes desses cineastas pernambucanos.

Além disso, as cenas de fato filmadas por Benjamin Abrahão nos remetem ao filme Memória do cangaço (1965) no qual Paulo Gil Soares, um realizador vinculado à geração do Cinema Novo e à chamada Caravana Farkas, nos dá a ver as cenas do grupo de Lampião captadas por Benjamin Abrahão, as quais são reapresentadas no Baile perfumado. Tal fenômeno poderia ser uma transposição, aliás. Mas, no que diz respeito às referências, há ainda outros dilemas a serem considerados no Baile perfumado, por exemplo, a locação no sertão que, contudo, aparece verdejante e com muita água, numa espécie de reversão de sua imagem mítica presente em tantos filmes cinemanovistas.

Esse confronto com o Cinema Novo de fato sugere uma crise dialética, conjugando-se, por um lado, como uma homenagem e, por outro, como uma necessidade de distanciamento dessa nova geração em relação àquela que lhe antecede, para poder afirmar o seu cinema. Nesse sentido, a trilha sonora tem um papel fundamental, porque reafirma uma identidade contemporânea local, ainda que a música do Manguebeat caracterize-se, por sua vez, por um movimento de busca simultânea de uma ancestralidade de ritmos locais, como o maracatu, e de uma vanguarda pop mundial. Por esse caminho, também poderíamos seguir na observação de outras referências recorrentes, como, por exemplo, ao gênero road movie, muitas vezes presente na filmografia em pauta, instigando uma intermidialidade entre cinema e música verificável em filmes diversos não só produzidos no Brasil (cf. PAIVA, 2007; NOGUEIRA, 2009). Se ainda não fica tão claro nas viagens de Benjamin Abrahão em sua busca pelo grupo de Lampião para fotografá-lo e filmá-lo, o caráter road movie do cinema pernambucano ficará cada vez mais evidente em outros filmes nos quais a música, como requisita o gênero, também tem um papel fundamental no deslocamento motorizado. 


\title{
Conclusão parcial
}

A noção de dissenso, segundo Rancière, evocada por Lúcia Nagib na perspectiva da intermidialidade surgida desde o cinema impuro, de acordo com Bazin, como discutimos anteriormente, certamente encontra no cruzamento entre o Árido Movie e o Manguebeat um ponto de inflexão instigante, inclusive, no que diz respeito à ideia de um dilema ou de uma crise dialética que, por todos os lados, revela-se na perspectiva de um regime estético localizável entre cinema e música. Só para recordar os termos de Rancière:

\begin{abstract}
No regime estético das artes, as coisas da arte são identificadas por pertencerem a um regime específico do sensível. Esse sensível, subtraído a suas conexões ordinárias, é habitado por uma potência heterogênea, a potência de um pensamento que se tornou ele próprio estranho a si mesmo: produto idêntico ao não-produto; saber transformado em não-saber; logos idêntico a um pathos, intenção do inintencional, etc. [grifos do autor] (RANCIËRE, 2005, p. 32-33).
\end{abstract}

Tal política da impureza, na atualização que faz Lúcia Nagib do regime estético de Rancière aplicado à intermidialidade, põe em xeque todo método historiográfico construído à revelia do objeto ou do seu contexto de experiência sensível, da relação entre arte e vida. Por outro lado, como vimos, as prerrogativas da impureza podem se conjugar com formulações epistemológicas daqueles que vêm pensando a questão em áreas diversas, por exemplo, Rajewsky, que nos serviu como parâmetro de investigação a partir dos três grupos de fenômenos que ela propõe.

Entretanto, o percurso tem os seus percalços. Basta observar, por exemplo, que, para o próprio Rancière, a noção de história só faz sentido se considerada como uma forma de ficção, dada, em sua visão, a superioridade da poesia sobre a história, já desde as proposições de Aristóteles.

A poesia não tem contas a prestar quanto à "verdade" daquilo que diz, porque, em seu princípio, não é feita de imagens ou enunciados, mas de ficções, isto é, de coordenações entre atos. Outra consequência tirada por Aristóteles é a da superioridade da poesia, que confere uma lógica causal a uma ordenação de acontecimentos segundo a desordem empírica deles. Dito de outro modo - e isso é evidentemente algo que os historiadores não gostam muito de olhar de perto -, a nítida separação entre realidade e ficção representa também a impossibilidade de uma racionalidade da história e de sua ciência (RANCIERE, 2005, p. 53-54).

Ainda assim, Rancière aparecerá como referência em outras abordagens so- 
bre métodos historiográficos e intermidialidade. Como exemplo, vale mencionar os estudos de Ágnes Pethö, que justamente se detém na questão metodológica, tentando demarcar o lugar da intermidialidade diante de outras possibilidades teóricas e históricas voltadas aos encontros entre mídias, por exemplo, as narrativas transmidiáticas, a convergência de mídias etc. Em seu livro, intitulado Cinema and intermediality: the passion for the in-between, mais precisamente no capítulo "Intermediality in film: a historiography of methodologies", Pethö (2011, p. 19-54) chega a um questionamento sobre quais seriam "os eixos de pesquisa histórica da intermidialidade no filme", apontando cinco paradigmas.

Resumidamente, podemos afirmar que o primeiro deles diz respeito ao filme como experiência sinestésica, sendo um exemplo, entre outros, Eisenstein e sua teoria da montagem, ao pressupor o filme como "música para os olhos" (apud Pethö, 2011 , p. 51), expressão que não por acaso está no título do filme Cartola, música para os olhos (2007) dos pernambucanos Lírio Ferreira e Hilton Lacerda. Haveria, segundo Eisenstein, uma estrutura rítmica capaz de ser transposta da música ao filme. Em suma, existiria uma correspondência possível entre todas as artes pela sinestesia, o cruzamento de sensações. A ideia aqui seria investigar, nos filmes do Árido Movie, momentos nos quais a montagem emula ritmos musicais, em especial, aqueles imbuídos como instantes de videoclipe, o que no Baile perfumado, como indicamos, acontece várias vezes, por exemplo, na própria sequência do baile dos cangaceiros.

O segundo paradigma apontado por Ágnes Pethö diz respeito ao filme como experiência transmidiática. A ênfase aqui está na narratologia, no aspecto narrativo que se sobrepõe ou relaciona distintas mídias, sendo várias as referências apontadas por ela, que inclui os primeiros formalistas russos, Kristin Thompson, David Bordwell, Edward Branigan e Seymour Chatman. Pensando livremente tantas possibilidades em relação ao nosso objeto, há uma dimensão narratológica que parece ser transposta da música ao filme, em especial, nos casos em que a música foi concebida anteriormente e à revelia da narrativa fílmica - como "Salustiano Song", em Baile perfumado. Mas a recíproca é verdadeira. Ou seja, os videoclipes das bandas que participam da trilha sonora, extraídos da narrativa fílmica, podem circular por outras janelas além da sala de cinema, por exemplo, na TV, com um valor acrescentado por sua presença no próprio filme. As estruturas narrativas tendem a se complementar, mesmo com as suas especificidades e distinções em razão dos diversos meios.

O terceiro paradigma considera o filme em comparação com outras artes (análises comparativas). Há uma conjunção pressuposta do cinema e ... pintura, música, arquitetura, televisão, novas mídias, etc. São conexões que pressupõem a pers- 
pectiva interartes e, nesse sentido, trata-se de um campo muito abrangente. Entram neste caso, por exemplo, as diversas teorias da adaptação, considerando-se inclusive os diferentes códigos de convenção das distintas artes ou mídias em suas possíveis relações. Pensando-se no exemplo da literatura, alguns filmes assumem em sua adaptação um estilo de "literariedade" ao inscreverem, como legendas na imagem, o próprio texto literário. Pensando-se no caso da pintura, haveria filmes marcados por uma "pictorialidade" instigada, entre outros, pela composição de molduras dentro da tela, manipulação de cores e encenação de quadros vivos. Pensando-se na música, há uma "musicalidade" a ser investigada nas articulações entre imagem e som, nos sentidos provocados pela trilha sonora em suas diversas articulações fílmicas. Como temos indicado, este último dado certamente é um fator distintivo do cinema pernambucano que aqui investigamos.

O quarto paradigma concerne à "historiografia paralaxe" ou "arqueologia de mídia" (PETHÖ, 2011, p. 36). A noção de "história paralaxe" tem a ver com a forma como passado e presente, e vice versa, podem se conectar, por exemplo, pela maneira como o primeiro cinema pode ser relacionado a produções contemporâneas, em perspectiva sincrônica, pressupondo, por exemplo, Méliès como um precursor da computação gráfica. Nesta seara está em pauta uma arqueologia do meio, inclusive no que concerne a materiais técnicos, formas de visionamento, etc. Deve-se a Catherine Russell a criação do termo "história paralaxe". Como explica a própria Russell: "o termo paralaxe é útil para descrever essa historiografia, porque invoca tanto uma mudança de perspectiva como um senso de paralelismo" (apud PETHÖ, 2011, p. 36). Aqui parece oportuno pensar, no caso do Baile perfumado, que a narrativa está diegeticamente localizada na década de 1930, quando Lampião e Maria Bonita vão a uma sala de cinema para assistir ao filme A filha do advogado (1926), de Jota Soares, ou quando Benjamin Abrahão persegue o bando de cangaceiros para filmá-lo. Desse modo, a perspectiva do cinema dentro do filme, construída nesses vários tempos, nos remete à dimensão paralaxe, uma vez que o objeto cinema é constantemente deslocado e observado sob distintos ângulos, do passado para o presente e vice versa, com materiais de arquivo e materiais atuais. Na perspectiva da trilha sonora, a história paralaxe seria possível de ser pensada a partir do caráter simultaneamente retrô e de vanguarda presente na música do Manguebeat, por exemplo, no caso de Chico Science, em sua pesquisa sobre o maracatu associada ao pop.

O quinto paradigma é o mais complexo, porque se desdobra em várias possibilidades em torno de retóricas do cinema intermidiático. Pethö apresenta um mapeamento de compreensões retóricas, organizando cinco grupos, cada qual respaldado 
por uma série de autores e referências. Resumindo, o primeiro diz respeito à intermidialidade como um sistema ou rede de convergência e transformação de mídias. O segundo, a uma experiência de percepção reflexiva, à busca de uma "diferença", de um "traço", a partir das noções de Derrida (2002). O terceiro, a um ato performativo, a uma ação que inclusive pode se dar como rivalidade entre as mídias. O quarto, à intermidialidade como um lugar transitório ou impossível, com base na noção de "heterotopia", segundo Foucault (1986). O quinto, a um domínio do "figural", à busca de tropos, figuras ou motivos, segundo Lyotard (2002), às "metalepses" (como investiga a própria Pethö) ou "ecfrases" e formas de "remediação", segundo Bolter \& Grusin (1999).

Diante de tantas possibilidades de retóricas intermidiáticas e da impossibilidade de discuti-las mais detidamente neste momento, não deixa de chamar a atenção como vários desses conceitos - diferença, traço, heterotopia, figural - de alguma forma pressupõem uma espécie de crise dialética, nos termos propostos por Nagib com base em Rancière. A questão do figural, por exemplo, aparece relacionada a Lyotard, para quem "o figural é um outro indizível necessariamente em trabalho dentro e contra o discurso, quebrando as regras de representação. Não é o oposto ao discurso, mas é o ponto por meio do qual as oposições que acionam o discurso são abertas para uma heterogeneidade radical ou para uma singularidade" [grifos do autor] (apud PETHÖ, 2011, p. 47). Entre os exemplos relacionados ao figural, surge então Histoire(s) du cinéma (1999), de Jean-Luc Godard. Depois de chamar a atenção para o fato de que nos filmes de Godard, como ecfrase, cada mídia se torna o espelho de outra, Pethö observa que...

Histoire(s) desenvolve uma fusão paradoxalmente única de colagem fotográfica, texto caligramático e aspectos musicais e espirituais da montagem cinematográfica, utilizando uma mídia aparentemente arcaica ou primitiva (com relativamente simples superposições, fades, inserts fotográficos, etc.), Godard efetivamente cria uma inter-mídia singular para o cinema falar sobre o cinema (PETHÖ, 2011, p. 46-47).

Não por coincidência, ela lembra que Rancière vê nessa obra de Godard a imagem como uma "promessa de carne", no sentido de algo tangível, corporal, e que o próprio Godard vê o cinema "nem como uma arte, nem como uma técnica" mas como "um mistério" (PETHO, 2011, p. 48). Nesse sentido, Histoire(s)... - que aqui também estamos assumindo como paradigma fundamental dos problemas colocados acerca das metodologias historiográficas pautadas na intermidialidade - se remete tanto à natureza material do cinema como também à transcendência dessa materialidade em suas figurações por vezes invisíveis, como a música, que, no entanto, sentimos. 


\section{Referências}

BARTHES, R. A câmara clara: nota sobre a fotografia. Rio de Janeiro: Nova Fronteira, 1984.

BAZIN, A. "Pour un cinéma impur - défense de l'adaptation”. In. Qu'est-ce que le cinéma? Paris: CERF, 2013, p. 81-106.

BERNARDET, J.-C. Historiografia clássica do cinema brasileiro: metodologia e pedagogia. São Paulo: Annablume, 1995.

BOLTER, J. D.; GRUSIN, R. Remediation: understending new media. MA: The MIT Press, 1999.

CASTRO, J. Geografia da fome: a fome no Brasil. Rio de Janeiro: O Cruzeiro, 1946. Geopolítica da fome. Rio de Janeiro: Casa do Estudante do Brasil, 1951.

. Homens e caranguejos. Porto: Ed. Brasília, 1967.

CHION, M. A audiovisão - som e imagem no cinema. Trad. Pedro Elói Duarte. Lisboa: Texto \& Grafia, 2011.

CUNHA, P. (org.). Relembrando o cinema pernambucano. Recife: Editora Massangana, 2006.

DELEUZE, G. A imagem-tempo: cinema 2. Trad. Rafael Godinho. Lisboa: Assírio e Alvim, 2006.

DELEUZE, G. A imagem-movimento: cinema 1. Trad. Souza Dias. 2a ed. Lisboa: Assírio e Alvim, 2009.

DERRIDA, J. Writing and difference. London/New York: Routledge \& Kegan Paulo, 2002.

FIGUEIRÔA, A. Cinema pernambucano: uma história em ciclos. Recife: Fundação de Cultura da Cidade do Recife, 2000.

FONSECA, N. Da lama ao cinema: interfaces entre o cinema e a cena mangue em Pernambuco. Dissertação (Mestrado em Comunicação) - Universidade Federal de Pernambuco, Recife, 2006.

FOUCAULT, M. "Of other spaces, heterotopias”. Diacritics, no. 16 (Spring), 22-27, 1986.

HANSEN, M. "The mass production of the senses: classical cinema as vernacular modernism”. In. GLEDHILL, C; WILLIAMS, L. (eds.). Reinventing film studies. London: Arnold, 2000, p. 332-351.

LEÃO, C. A maravilha mutante: batuque, sampler e pop na música pernambucana dos anos 90. Dissertação (Mestrado em Comunicação) - Universidade Federal de Pernambuco, Recife, 2002. 
LEÃO, C. A nova velha cena: a ascensão da vanguarda mangue no campo da cultura recifense. Tese (Doutorado em Sociologia) - Universidade Federal de Pernambuco,Recife, 2008.

LYOTARD, J. F. Discours, figure. Paris: Klincksieck, 2002.

NAGIB, L. O cinema da retomada - depoimento de noventa cineastas dos anos 90 . São Paulo: Editora 34, 2002.

"Politics of impurity". In. NAGIB, L.; JERSLEV, A. (eds). Impure cinema: intermedial and intercultural approaches to film. London, New York: I.B. Taurus, 2014, p. 21-39.

NOGUEIRA, A. M. C. O novo ciclo do cinema em Pernambuco - a questão do estilo. Recife: Editora da UFPE, 2009.

ODIN, R. "Filme documentário, leitura documentarizante". Significação, n 37 , 2012, p. 10-30. Disponível em: http://www.usp.br/significacao/pdf/37_odin.pdf

PAIVA, S. "Um road movie na rota do sertão-mar". In: MACHADO, R.; SOARES, R.L.; ARAÚJO, L.C. (orgs.). Estudos de cinema Socine. São Paulo: Annablume, 2007, p. 171-179.

. "Do curta ao longa: relações estéticas no cinema contemporâneo de Pernambuco". In. HAMBURGER, E. et al. (orgs.). Estudos de cinema Socine. Local da publicação, editora, 2008, p. 99-107.

."O deslocamento do sujeito masculino no sertão contemporâneo: estudos de caso na literatura e no cinema”. In. VICENTE, A.L.; JUNQUEIRA, R.S. (org.). Teatro, cinema e literatura: confluências. São Paulo: Cultura Acadêmica, 2014, p. 75-92.

PETHÖ, A. "Intermediality in film: a historiography of methodologies". In. Cinema and intermediality: the passion for the in-between. UK: Cambridge Scholars Publishing, 2011, p. $19-54$.

RAJEWSKY, I. "A fronteira em discussão: o status problemático das fronteiras midiáticas no debate contemporâneo sobre intermidialidade". In: DINIZ, T.F.N.; VIEIRA, A.S. (orgs.). Intermidialidade e estudos interartes: desafios da arte contemporânea 2. Belo Horizonte: Rona Editora: FALE/UFMG, 2012, p. 51-74.

RANCIÈRE, J. A partilha do sensivel: estética e política. Trad. Mônica Costa Netto. São Paulo: Editora 34, 2005.

Dissensus: On politics and aesthetics. Trad. Steven Corcoran. New York/ London, Continuum, 2010.

VARGAS, H. Hibridismos musicais de Chico Science \& Nação Zumbi. Cotia, SP: Ateliê Editorial, 2007. 


\section{Referências Audiovisuais}

A FILHA do advogado. Jota Soares, Brasil, 1926.

BAILE perfumado. Lírio Ferreira e Paulo Caldas, Brasil, 1996.

CARTOLA, música para os olhos. Lírio Ferreira e Hilton Lacerda, Brasil, 2007.

DOGVILLE. Lars von Trier, Dinamarca, Suécia, Noruega, Finlândia, Reino Unido, França, Alemanha e Países Baixos, 2003.

HISTOIRE(S) du cinema. Jean-Luc Godard, França, 1999.

MEMÓRIA do cangaço. Paulo Gil Soares, Brasil, 1965.

submetido em: 26 fev. 2016 | aprovado em: 24 jun. 2016. 